\title{
Caracterização sazonal de acúmulos isolados de própolis em colônias de Plebeia emerina (Hymenoptera, Apidae) no sul do Brasil
}

\author{
Camila G. dos Santos, Karina C. dos Santos, Flávia P. Tirelli \& Betina Blochtein
}

Laboratório de Entomologia, Faculdade de Biociências, Pontifícia Universidade Católica do Rio Grande do Sul, Av. Ipiranga, 6681, prédio 12-D, 4ªndar, 90619-900 Porto Alegre, RS, Brasil. (camilasantos@pucrs.br; betinabl@pucrs.br)

\begin{abstract}
Seasonal characterization of isolated propolis clusters in Plebeia emerina (Hymenoptera, Apidae) colonies in the south of Brazil. In colonies of stingless bees, propolis is used for many applications, such as in raw material for constructions and for their defense against enemies. There are records of viscous propolis storage, in form of isolated clusters. In this work, the seasonal characterization of area, number and spatial distribution of isolated propolis clusters in Plebeia emerina (Friese, 1900) colonies is proposed. Colonies were evaluated between October/2003 and September/2004, by measuring in a monthly basis the isolated propolis clusters and recording the relative position of these clusters within the beehives. Between October and March, the area of propolis clusters in the colonies varied between 0.50 and $4.92 \mathrm{~cm}^{2}$, and the number of clusters from 3 to 16. In the period from April to September, the area varied between 4.54 and $18.48 \mathrm{~cm}^{2}$, and the number of clusters from 9 to 36 . It is suggested that the increase of clustered propolis may be related to the preparation of the colonies for the autumn-winter seasons, when there is a reduced collection of the product. The seasonal analysis of the distribution of isolated propolis storages corroborates with the total area records, indicating a preference of the anterior position of the colony for propolis clustering. This fact strengthens the hypothesis that viscous propolis of isolated deposits is used for defense, mainly along the entrance of the colonies.
\end{abstract}

KEYWORDS. Stingless bees, defense, Meliponini, propolis, seasonality.

RESUMO. Em colônias de abelhas sem ferrão a aplicação da própolis é ampla, sendo utilizada como matéria-prima nas construções e defesa contra inimigos. Há registros de armazenamento de própolis viscosa, sob forma de acúmulos isolados. Neste trabalho propõe-se a caracterização sazonal da área, do número e da distribuição espacial dos acúmulos isolados de própolis em colônias de Plebeia emerina (Friese, 1900). Colônias foram avaliadas entre outubro/2003 e setembro/2004, medindo-se mensalmente os acúmulos isolados de própolis e registrando-se a posição relativa dos mesmos nas colméias. Entre outubro e março, a área dos acúmulos de própolis nas colônias variou entre 0,50 e $4,92 \mathrm{~cm}^{2}$ e o número de acúmulos foi de 3 a 16 . No período de abril a setembro, a área foi de 4,54 a $18,48 \mathrm{~cm}^{2}$ e o número de acúmulos de 9 a 36. Sugere-se que o aumento da própolis acumulada possa estar relacionado à preparação das colônias para o outonoinverno quando a coleta do produto é reduzida. A análise sazonal da distribuição dos depósitos isolados de própolis corrobora com os registros da área total, indicando preferência da posição anterior da colônia para acumular a própolis. Esta constatação fortalece a hipótese do uso da própolis viscosa dos depósitos isolados na defesa, principalmente junto à entrada das colônias.

PALAVRAS-CHAVE. Abelhas sem ferrão, defesa, Meliponini, própolis, sazonalidade.

As resinas, coletadas em diversas espécies vegetais pelas abelhas sociais, são o principal constituinte da própolis. As abelhas domésticas (Apis mellifera Linnaeus, 1758) utilizam a própolis predominantemente na vedação e desinfecção das colméias (MEYER, 1956). Em colônias de abelhas sem ferrão (Meliponini) a aplicação da própolis é mais ampla, servindo também para a construção de estruturas externas (tubos de entrada) e internas (favos de cria, lamelas de invólucro e potes de alimento) das colônias e para defesa contra inimigos. Nos casos em que a própolis é utilizada nas construções ocorre uma mistura, em proporções variáveis, com outros componentes como cera, barro, fibras vegetais e sementes (Nogueira-Neto, 1970, 1997; Michener, 1974, 2000; VENTURIERI et al., 2003).

As entradas das colônias de abelhas sem ferrão são distintas e características para cada espécie. Em algumas, gotículas de própolis pegajosa são notadas em suas entradas, impedindo o acesso de inimigos (KERR \& Lello, 1962; Nogueira-Neto, 1970, 1997; Michener, 1974). Segundo NogueiRA-Neto $(1970,1997)$, o armazenamento de própolis, praticamente sem mistura, sob forma de acúmulos isolados, pode ser observado em colônias de jataí, Tetragonisca angustula (Latreille, 1811) e nas espécies de Plebeia Schwarz, 1938. Juliani (1967), WitTMANn (1989) e VAN BeNTHEM et al. (1995) acrescentam que em P. julianii Moure, 1962, P. wittmanni Moure \& Camargo, 1989 e P. remota (Holmberg, 1903), respectivamente, são observados estoques de própolis dentro das colônias. NogueIRA-Neto $(1970,1997)$ relata que essa própolis apresenta-se viscosa e grudenta e é usada para calafetar fendas da colméia e para uma defesa mais direta da colônia. Pick \& Blochtein (2002) corroboram que operárias de P. saiqui (Holmberg, 1903), quando ameaçadas destacam porções da própolis armazenada e investem contra os inimigos, colando-as em seus corpos.

A exemplo de outros recursos coletados, o ingresso de própolis nas colônias depende das atividades de voo de operárias e está relacionado a condições externas como a disponibilidade de recursos vegetais (PIERROT \& SCHLINDWEIN, 2003), fatores abióticos (HiLÁRIO et al., 2000, 2001; Souza et al., 2006) e condições internas das colônias. Esse último fator pode ser evidenciado pelo número de crias nascentes e diâmetro dos favos (AIDAR, 1996; HiLÁRIo et al., 2000). Mudanças nas condições das colônias, decorrentes de alterações de seu estado fisiológico, em regiões frias, podem ocasionar a 
interrupção temporária da postura pela rainha (diapausa reprodutiva) e consequentes alterações comportamentais das operárias, como a redução das atividades de voo. Este comportamento ocorre sob condições ambientais adversas (outono-inverno) em clima subtropical e foi registrado em $P$. julianii (Juliani, 1967), $P$. droryana (Friese, 1900) (Terada et al., 1975), P. saiqui (PICK \& Blochtein, 2002), P. wittmanni (Wittmann, 1989) e $P$. remota (VAn Benthem et al., 1995; RiBeiro et al., 2003), parecendo ocorrer também em Plebeia emerina (Friese, 1900) (observação dos autores).

A mensuração de acúmulos isolados de própolis é inédita em Meliponini e no presente trabalho objetivouse caracterizar sazonalmente a área, o número e a distribuição espacial dos acúmulos isolados de própolis viscosa em colônias de $P$. emerina, a qual distribui-se desde o Paraná até o Rio Grande do Sul, inclusive em áreas urbanas (Hoffmann \& WittMann, 1990; Alves dos SANTOS, 1999; SilveIRA et al., 2002; STEINER et al., 2006)

\section{MATERIAL E MÉTODOS}

Manutenção das colônias. Duas colônias de $P$. emerina ( $\mathrm{C} 1$ e $\mathrm{C} 2$ ) foram transferidas de caixas rústicas para colméias padronizadas de madeira $(37 \times 24 \times 18 \mathrm{~cm})$, em agosto/2003 e acompanhadas até setembro/2004, no meliponário instalado no Campus da PUCRS (3003'38.64"S, 051¹0'33.18”W), em Porto Alegre, RS, Brasil. Cada colônia estava comunicada ao exterior por meio de uma mangueira plástica $(\varnothing 6 \mathrm{~mm})$ que atravessava a parede do meliponário. Alimento adicional (1:1 água e açúcar) foi fornecido, ad libitum, em tubos de ensaio tampados nas extremidades com algodão, durante o período de outono e inverno.

Acúmulos isolados de própolis. A partir de observações mensais do interior das caixas, cada acúmulo isolado de própolis foi representado graficamente em pranchas, de acordo com a sua localização e área. Os acúmulos com mais de $2 \mathrm{~mm}$ de diâmetro foram mensurados com régua milimetrada e considerando-se a forma subcircular dos acúmulos estimou-se a área dos mesmos com base no cálculo da elipse $(A=\pi . a . b)$ sendo $a$, raio maior e b, raio menor. Para a análise da distribuição espacial dos acúmulos de própolis nas caixas considerouse três unidades: anterior, aquela em que está localizada a entrada da colônia e contêm potes de armazenagem de alimento; a média, correspondendo àquela área contendo os favos de cria e a posterior, com potes de alimento e o local da descarga dos detritos da colônia (Fig. 1). A área total dos acúmulos de própolis foi avaliada em cada unidade.

Para o estudo da sazonalidade, as amostragens dos meses de outubro a março são correspondentes às estações primavera-verão e as dos meses de abril a setembro abrangem o outono-inverno. Em Porto Alegre, considerando-se as normais climáticas, as temperaturas mínimas e máximas médias no período de outubro a março atingem $18,13^{\circ} \mathrm{C}$ e $28,4^{\circ} \mathrm{C}$ e de abril a setembro de $12,16^{\circ} \mathrm{C}$ e $21,65^{\circ} \mathrm{C}$. A pluviosidade média de outubro a março atinge $99 \mathrm{~mm}$ e de abril a setembro alcança 119,33 mm (IPAGRO, 1989).

Análise estatística. Aárea dos acúmulos de própolis em cada colônia e o número de acúmulos conjuntamente nas colônias, relacionados às estações primavera-verão e outono-inverno foram submetidos aos testes " $U$ " de Mann-Whitney e "t" de Student, respectivamente. Os fatores sazonalidade e colônia foram submetidos à análise de variância (ANOVA), dois fatores, alfa $=0,05$. Os testes estatísticos foram executados no programa GraphPad Prim 5.0 (Motulsky, 1999).

\section{RESULTADOS E DISCUSSÃO}

Acúmulos de própolis. A análise dos resultados indica que os estoques de própolis nos acúmulos isolados diferem sazonalmente em colônias de P. emerina (Tab. I). Esse resultado reforça a relevância das estações do ano no que tange o comportamento desta espécie.

Nos períodos de primavera-verão e outonoinverno, a área total dos acúmulos isolados de própolis diferiu estatisticamente nas duas colônias ( $\mathrm{C} 1, \mathrm{U}=2432$, $\mathrm{p}<0,0001$ e $\mathrm{C} 2, \mathrm{U}=1251, \mathrm{p}=0,0249)$. Nesses períodos, $\mathrm{o}$ número de acúmulos de própolis, nas colônias conjuntamente, apresentou diferenças estatísticas $(\mathrm{t}=5.974, \mathrm{p}<0,0001)$. A área total dos acúmulos de própolis variou de 0,50 a $4,92 \mathrm{~cm}^{2}$ e o número de acúmulos foi de 3 a 16 entre outubro e março. Entre abril e setembro, oscilou de 4,54 a $18,48 \mathrm{~cm}^{2}$ e o número de acúmulos foi de 9 a 36 (Fig. 2). Estas diferenças evidenciadas entre as colônias, na área e no número de acúmulos, possivelmente estão relacionadas ao tamanho populacional, o qual reflete no ingresso de própolis coletada pelas operárias e sua utilização nas construções e defesa dos ninhos.

Nos meses de outubro a março, a variação da área e do número de acúmulos de própolis, em ambas as

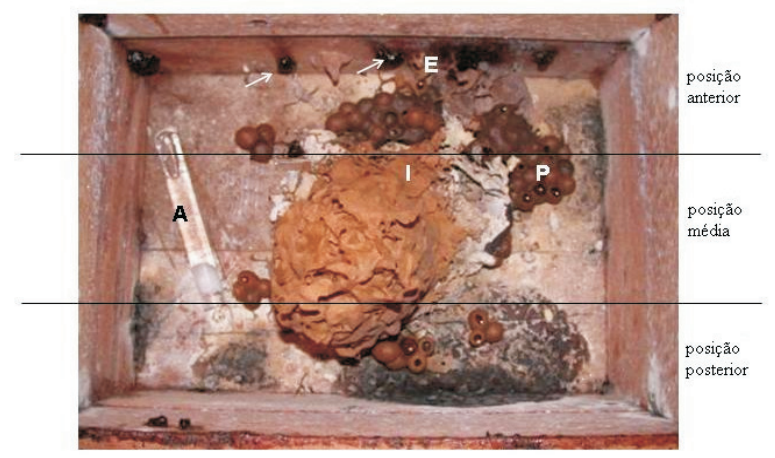

Figura 1. Vista superior de colônia de Plebeia emerina (Friese, 1900). Acúmulo isolado de própolis (seta), entrada (E), invólucro dos favos de cria (I), potes de alimento (P) e alimentador artificial (A).

Tabela I. Análise de variância (ANOVA dois fatores, alfa $=0,05$ ) na influência dos fatores sazonalidade e colônia referente à área dos acúmulos de própolis. Asterisco indica influência significativa $($ alfa $=0,05)$.

\begin{tabular}{lccccc}
\hline Parâmetro & Fator & $\begin{array}{c}\text { Graus de } \\
\text { Liberdade }\end{array}$ & $\begin{array}{c}\text { Soma dos } \\
\text { Quadrados }\end{array}$ & $\mathrm{F}$ & $\mathrm{p}$ \\
\hline Área dos & Sazonalidade & 1,0 & 3,733 & 10,29 & $0,0015^{*}$ \\
acúmulos & Colônia & 1,0 & 0,5542 & 1,53 & 0,2172 \\
de própolis & Interação & 1,0 & 0,9336 & 2,57 & 0,1095 \\
$\left(\mathrm{~cm}^{2}\right)$ & Erro & 369,0 & 133,8 & & \\
& Total & 372,0 & & & \\
\hline
\end{tabular}


colônias, pode estar relacionada à intensa utilização da própolis na construção de estruturas das colônias (favos de cria, invólucro e potes de alimento). Neste período, na mesma região geográfica, operárias de $P$. saiqui exibem intensas atividades internas às colônias que demandam ampla utilização de própolis (PICK \& BlochteIn, 2002).

No período de abril a setembro, o aumento da área de própolis acumulada, assim como do número de acúmulos, foi constatado nas duas colônias. Destaca-se um aumento expressivo, na colônia 1, nos meses de abril e maio e posterior manutenção deste estoque durante os meses seguintes, enquanto que na colônia 2 observa-se um aumento gradual no estoque da própolis. A diferença do estoque nas duas colônias poderia ser atribuída a distintas proporções tanto na coleta quanto no consumo da própolis. Condições intraespecíficas e preparação interna das colônias para o período de condições meteorológicas adversas (outono-inverno), marcadas pelas baixas temperaturas podem explicar essa questão. Nesta época as abelhas diminuem suas atividades com construções no interior das colônias, que demandam própolis, devido à redução ou ausência total de favos de cria (diapausa reprodutiva) (IMPERATRIz-FonsECA \& Oliveira, 1976) e de novos potes de alimento (Pick \& Blochtein, 2002). Consequentemente, as operárias maximizam seus esforços na manutenção da própolis nos acúmulos.

Distribuição espacial. Na porção anterior das colônias 1 e 2 registrou-se o maior percentual de própolis acumulada (74,70 e $53,07 \mathrm{~cm}^{2}$, respectivamente) ao longo do ano (Fig. 3). Este fato deve-se, provavelmente, à funcionalidade da própolis na defesa das colônias, principalmente junto às entradas. Estudos anteriores reforçam que operárias de espécies de Plebeia utilizam intensamente a própolis pegajosa diretamente contra inimigos naturais (KeRR \& LeLLO, 1962; JULIANI, 1967; Van Benthem et al., 1995; Pick \& Blochtein, 2002).

No período de atividades mais intensas das abelhas (primavera-verão) a área de própolis acumulada na porção anterior das colônias representou cerca de $80-90 \%$ do total, enquanto no outono e inverno o maior percentual nesta posição foi de $60 \%$ a $70 \%$ do total da própolis (Fig. 4).

A posição média das colônias foi a menos utilizada pelas operárias durante todo o período de estudo, enquanto que na posição posterior, principalmente, nos

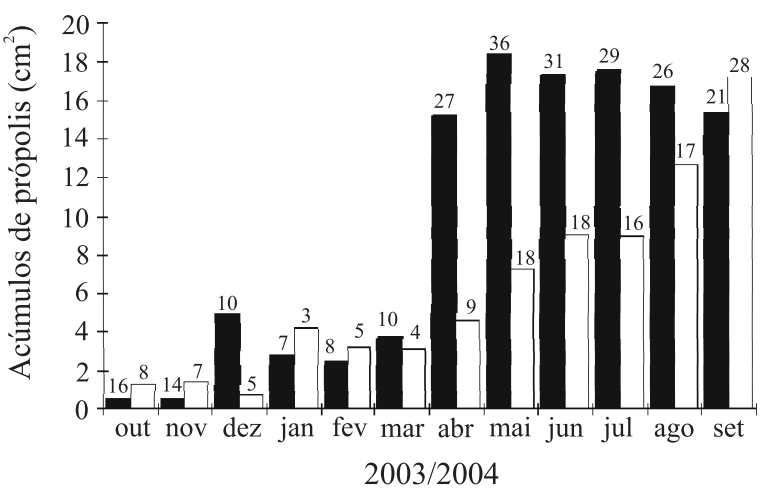

Figura 2. Área total dos acúmulos isolados de própolis em colônias de Plebeia emerina (Friese, 1900), em Porto Alegre, RS. O número total de acúmulos de própolis mensurados apresenta-se acima das barras ( colônia 1; $\square$ colônia 2).

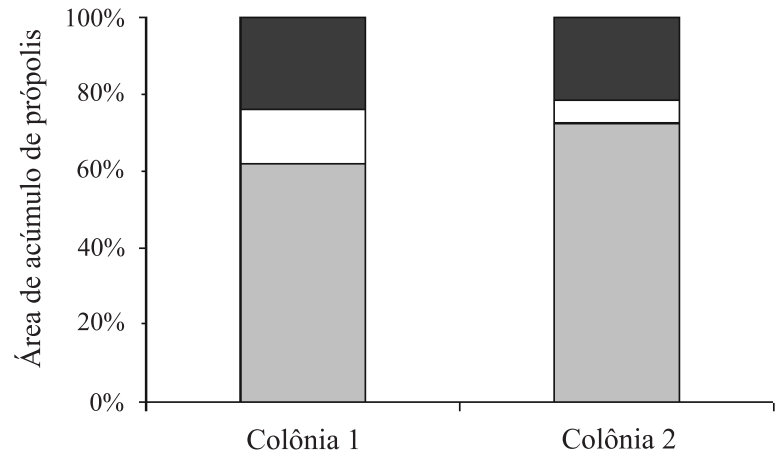

Figura 3. Distribuição espacial dos acúmulos isolados de própolis em colônias de Plebeia emerina (Friese, 1900), no período de outubro/2003 a setembro/2004, em Porto Alegre, RS. Posição na colônia: $\square$ anterior; $\square$ média; $\square$ posterior.

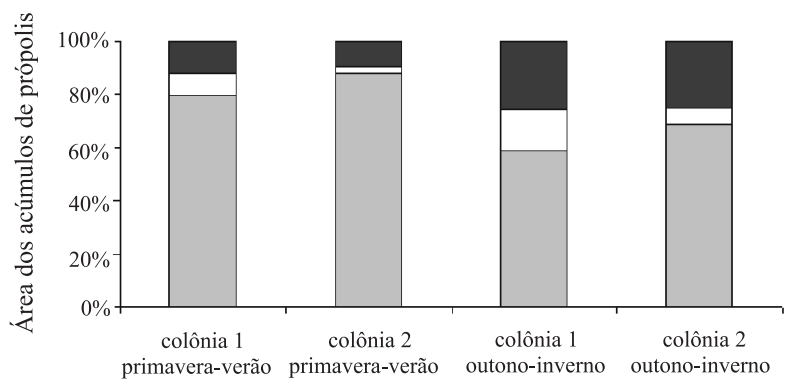

Figura 4. Distribuição espacial dos acúmulos de própolis, nos períodos de primavera-verão e outono-inverno em colônias de Plebeia emerina (Friese, 1900), durante o período de outubro/ 2003 a setembro/2004, em Porto Alegre, RS. Posição na colônia: $\square$ anterior; $\square$ média; $\square$ posterior.

períodos de outono-inverno foi estocada quantidade expressiva de própolis (Fig. 4). Observações de depósitos de detritos na posição posterior nas caixas em $P$. emerina sugerem a necessidade de quantidades de própolis nesta área das colônias, devido as suas reconhecidas propriedades anti-sépticas (MARCUCCI, 1995; MirzoEVA et al., 1997; Burdock, 1998; KuJumgiev et al., 1999). Especialmente no período de condições meteorológicas adversas as operárias reduzem suas atividades e necessitam exercer maior controle sobre o desenvolvimento de microorganismos patógenos.

Enfatiza-se que a quantidade de própolis acumulada nas colônias de $P$. emerina está relacionada com as estações do ano e apresenta-se maior no período de outubro-inverno. Além disso, este estudo fortalece a hipótese que a localização dos acúmulos isolados de própolis viscosa, preferencialmente na porção anterior das colônias junto à entrada, facilita sua disponibilização na área de maior risco de invasão por intrusos. O conhecimento sobre o uso da própolis por P. emerina é importante para a conservação e manejo racional da espécie.

Agradecimentos. Ao Prof. Dr. Nelson Fontoura (PUCRS) pelas sugestões relevantes a esse manuscrito e a Dra. Daniela Rodrigues pela orientação e auxílio das análises estatísticas.

\section{REFERÊNCIAS BIBLIOGRÁFICAS}

AIDAR, D. S. 1996. A mandaçaia: biologia de abelhas, manejo e multiplicação artificial de colônias de Melipona 
quadrifasciata Lep. (Hymenoptera, Apidae, Meliponinae). Ribeirão Preto, Sociedade Brasileira de Genética. Série Monografias, n. 4. 103p.

Alves dos Santos, I. 1999. Distribuição vertical de uma comunidade de abelhas (Hymenoptera, Apoidea) do Rio Grande do Sul. Revista Brasileira de Entomologia 43(3/4):225-228.

Burdock, G. A. 1998. Review of the biological properties and toxicity of bee propolis. Food Chemical Toxicology 36:347363.

Hilário, S. D.; Imperatriz-fonseca, V. L. \& Kleinert, A. M. P. 2000. Flight activity and colony strength in the stingless bee Melipona bicolor bicolor (Apidae, Meliponine). Revista Brasileira de Biologia 60(2):299-306.

2001. Responses to climatic factors by foragers of Plebeia pugnax Moure (in litt.) (Apidae, Meliponinae). Revista Brasileira de Biologia 61(2):191-196.

Hoffman, M. \& Wittmann, D. 1990. Bees of Rio Grande do Sul, southern Brazil (Insecta, Hymenoptera, Apoidea). Iheringia, Série Zoologia, 70:17-43.

Imperatriz-FonseCA, V. L. \& Oliveira, M. A. C. 1976. Observations on a queenless colony of Plebeia saiqui (Friese) (Hymenoptera, Apidae, Meliponinae). Boletim de Zoologia Universidade de São Paulo 1:299-312.

IPAGRO (Instituto de Pesquisas Agronômicas). 1989. Atlas Agroclimático do Estado do Rio Grande do Sul. Porto Alegre, IPAGRO. v.1. 102p.

Juliani, L. 1967. A descrição do ninho e alguns dados biológicos sobre a abelha Plebeia julianii Moure, 1962 (Hymenoptera, Apidae). Revista Brasileira de Entomologia 12:31-58.

Kerr, W. E. \& Lello, E. 1962. Sting glands in stingless bees - a vestigial character. Journal New York Entomological Society 70:190-214.

Kujumgiev, A.; Tsvetkova, I.; Serkedjieva, Y. U.; Bankova, V.; Christov, R. \& Popov, S. 1999. Antibacterial, antifungal and antiviral activity of propolis of different geographic origin. Journal of Ethnopharmacology 64:235-240.

Marcucci, M. C. 1995. Propolis: chemical composition, biological properties and therapeutic activity. Apidologie 26:83-99.

Meyer, W. 1956. Propolis bees and their activities. Bee World 37(2):25-36.

Michener, C. D. 1974. The social behaviour of the bees. A comparative study. Cambridge, Harvard University. 404p. . 2000. The bees of the world. Baltimore, Johns Hopkins University. 913p.

Mirzoeva, O.; Grishanin, R. \& Calder, P. 1997. Antimicrobial action of propolis and some of its components: the effects of growth, membrane potencial and motility of bacteria.
Microbiological Research 152:239-246.

Motulsky, H. 1999. Analyzing data with graph pad prism software. San Diego, Graph Pad Software. 397p.

Nogueira-Neto, P. 1970. A Criação de abelhas indígenas sem ferrão. São Paulo, Tecnapis. 365p.

1997. Vida e criação de abelhas indígenas sem ferrão. São Paulo, Nogueirapis. 446p.

Pick, R. A. \& Blochtein, B. 2002. Atividades de vôo de Plebeia saiqui (Holmberg, 1903) (Hymenoptera, Apidae, Meliponinae) durante o período de postura da rainha e em diapausa. Revista Brasileira de Zoologia 19(3):827-839.

Pierrot, L. M. \& Schlindwein, C. 2003. Variation in daily flight activity and foraging patterns in colonies of uruçu (Melipona scutellaris, Apidae, Meliponini). Revista Brasileira de Zoologia 20(4):565-571.

Ribeiro, M. F.; Imperatriz-Fonseca, V. L. \& Santos Filho, P. S. 2003. A interrupção da construção de células de cria e postura em Plebeia remota (Holmberg) (Hymenoptera, Apidae, Meliponini). In: Melo, G. A. R \& Alves dos Santos, I. eds. Apoidea Neotropica: homenagem aos 90 anos de Jesus Santiago Moure. Criciúma, UNESC. p.177-188.

Silveira, F. A.; Melo, G. A. R. \& Almeida, E. A. B. 2002. Abelhas Brasileiras: Sistemática e Identificação. Belo Horizonte, F. A. Silveira. 253p.

Souza, B. A.; Carvalho, C. A. L. \& Alves, R. M. O. 2006. Flight activity of Melipona asilvai Moure (Hymenoptera: Apidae). Brazilian Journal Biology 66(2B):731-737.

Steiner, J.; Harter-Marques, B.; Zillikens, A. \& Feja, E. P. 2006. Bees of Santa Catarina Island, Brazil a first survey and checklist (Insecta: Apoidea). Zootaxa 1220:1-18.

Terada, Y.; Garófalo, C. A. \& Sakagami, S. F. 1975. Age-survival curves for workers of two eusocial bees Apis mellifera and Plebeia droryana in a subtropical climate, with notes on queen polyethism in $P$. droryana. Journal Apicultural Research 14(3/4):161-170.

Van Benthem, F. D. J.; Imperatriz-Fonseca, V. L. \& Velthuis, H. W. 1995. Biology of the stingless bee Plebeia remota (Holmberg). Observation and evolutionary implications. Insectes Sociaux 42(1):71-87.

Venturieri, G. C.; Raiol, V. F. O. \& Pereira, C. A. B. 2003. Avaliação da introdução da criação racional de Melipona fasciculata (Apidae, Meliponina), entre os agricultores familiares de Bragança, PA, Brasil. Biotropica 2:1-7.

WitTMAnN, D. 1989. Nest architecture, nest site preferences and distribution of Plebeia wittmanni Moure \& Camargo, 1989 in Rio Grande do Sul, Brazil (Apidae, Meliponinae). Studies on Neotropical Fauna and Environment 24:17-23. 